\title{
Gender and Citizenship in the Middle East
}

Suad Joseph, ed. Syracuse: Syracuse University Press, 2000. 400 pages.

The fourteen case studies that compose this volume address the various institutional, economic, social, cultural, and political dimensions of the debate on gender and citizenship in the Middle East. Using a crosscultural comparative approach, the theoretical introduction as well as the individual case studies seek to challenge dominant (especially western) feminist models of analysis of the question of gender and citizenship in the Middle East. The validity of dominant feminist paradigms is questioned by introducing new social and cultural variables, and putting at stake a number of traditionally unquestioned or unrecognized modes of identity formation, such as kinship, family, tribe, and sects, which critically affect a woman's citizenship status. The volume purports to contest essentializing myths about the Middle East that artificially give it a character of regional coherence, and homogenize the image of Middle Eastern women as a category. The volume thus theorizes the gendering of citizenship from the largely unexplored perspectives that open up from introducing the above variables, toward a better understanding of the complex nature of the laws (religious, political, patriarchal and patrilineal) governing the construction of a gendered citizenship in the Middle East.

The theoretical introduction to the volume outlines the dynamics of a number of points of departure that presumably underlie the writing of the "legal subject in the Middle East," namely nations, states, religion, family. The contributors seem to all concede that "most Middle Eastern states have cemented the linkage between religious identity, political identity, patrilineality, and patriarchy - that is, between religion, nation, state, and kinship." The Middle Eastern countries studied in the volume are divided regionally into four areas: North Africa (including Egypt, Algeria, Tunisia and Morocco); Eastern Arab States (including Lebanon, Palestine, Jordan and Iraq); the Arab Gulf (including Saudi Arabia, Kuwait and Yemen); the Non-Arab Middle East (including Turkey, Iran, and Jewish and Palestinian Arab women in Israel). The authors of the various case studies conducted an exhaustive investigation of the related topics, albeit with a notable difference of outlook varying between liberal individualistic and communitarian conservative positions.

The methodological approach adopted by various contributors draws 
mainly on key concepts and analytical categories that are directly related to social sciences and international human rights law in regards to various social, cultural and political mechanisms and processes involved in the construction of citizenship. In its methodology, general purpose and theoretical concerns, this volume is intended to be the second of a twovolume project, and, more particularly, follows closely in the footsteps of the investigative project undertaken by the authors of the sister volume Citizenship and State in the Middle East (2000), edited by Nils Butenschon, Uri Davis, and Manuel Hassassian. The readers of the second volume will find the ethnographic richness of the painstakingly documented case studies comparable to that of the first volume, if not more extensive, as it covers a greater number of regional and cultural contexts in the Middle East (that includes North Africa and Egypt) than does the former volume. Both volumes address the contemporary relevance of a pluralistic approach to account for the pitfalls and contradictions inherent in modern conceptions of citizenship in the Middle East. They place a special emphasis on the incompatibility of certain sociocultural forms of community organization (such as kinship, tribal allegiance, and patrilineality) with modern notions of citizenship. The second volume highlights the conflicting ways in which these forms of community-based citizenship operate, by discussing how being caught at the intersection of the various forms of membership in a community has critical consequences for women's citizenship rights.

Gender and Citizenship in the Middle East is compelling in a number of important respects. The very scope of the book covers a broad research base that, although it remains largely heuristic in its thrust, offers a valuable comparative outlook that makes possible a shift in the traditional feminist paradigms applied to the analysis of gender and citizenship in the Middle East. This comprehensive study has the strength of detailing the various ways in which constitutional provisions for women's rights and responsibilities are formulated across different Middle Eastern states. In their profiling of women as they figure in the "differing relationship of men and women to the laws and practices of citizenship in their states," the contributors to this volume argue that women's rights as free individuals and citizens are eclipsed by the fact of their gender. Their approach offers groundbreaking alternative tools of adequate investigation, that promise to be more representative of the diversity of the contexts within which such a gendered citizenship is to be assessed, and of the multiplicity of boundaries 
through which Middle Eastern women define their interests, commitments and various forms of membership in a community such as class, race, ethnicity, religion, tribe, and so on.

Of particular relevance to Islamic thought is the volume's critical revision of dominant feminist discourses that establish an essentialist correlation between Middle Eastern women's gendered citizenship status and Islamic shari'a or laws. The contributors' individual studies illustrate the ways in which such an assumption leads to a false understanding of the true determinants of Middle Eastern women's identity as citizens, and overlooks their complexity. By documenting how kinship, family ties, patriarchy and patrilineality have been to a great extent intrinsically linked to various modalities of religious and state authority, the contributors to this volume suggest that state and religious authorities do not figure in those cultural contexts as autonomous spheres of universal laws. In other words, laws legislated by state and religious institutions do not seem wholly to transcend gender as well as other types of social and cultural hierarchies in their definition of the rights and responsibilities of men and women. The authors seem to agree that the citizen's relationship to the state (as a guarantor of equality before the law) is often mediated through the particularistic ties of kinship, ethnicity and tribe or patriarchal religious forms of belonging or allegiance, understood as having patriarchy as its foundational unit that consistently privileges the male. The case study on Sudan, for example, is a powerful critique in that it introduces the important conceptual distinction of Arab/Muslim as discrete categories deployed for the construction of the Sudanese citizen. By arguing that the Arab-based constructions of identity reinforce patriarchal structures of domination, the author of the case study on Sudan describes the new model of Sudanese citizenship that emerged during the recent dramatic changes in the Sudanese political scene: a model that is free of gender hierarchical structures, and finds its main inspiration and endorsement in the Islamic shari'ah. However, the examination of the resources of shari'ah and its positive provisions for the experience of an authentic citizenship and political participation is undercut by the appropriation of the individual vs. community dichotomy as bases for alternative conceptions of citizenship. This opposition has the disadvantage of presenting the individual and the community as mutually exclusive categories for the construction of citizenship. The theoretical points of departures outlined in the introductory chapter seem to consider religion as being merely one among many 
modes of identity construction (such as kinship, patriarchy, class) in which the individual has an identity exclusively by his/her belonging to a particular community, and not in relation to a set of universal laws or values. The contributors' analysis of the place of Islamic shari'ah in the process of constructing a female citizenship is therefore a site of conflicting interpretations. Although the more secular points of view in the volume provide an exhaustive analysis of the essentially hierarchical nature of kin-based formations, the assumption that Islamic shari'ah cannot be accommodated to the needs of a pluralistic society, nor be reconciled with modern notions of citizenship is not documented, and therefore problematic.

This volume includes an interesting foreword written by Deniz Kandiyoti, where she summarizes the ways in which this study inscribes itself in the contemporary discourse on citizenship and political participation. There is also a preface by the major four editors of the previous volume - Nils Butenschon, Uri Davis, Manuel Hassassian, and Suad Joseph - which summarizes the history of the project as well as comments on its particular contributions to the field of social sciences. There is also a comprehensive listing of works cited for those interested in undertaking further research in this direction. And finally, there is a very useful index section which is fairly exhaustive in its grouping of various key subjects, and which offers an easy thematic cross-referencing between various chapters. Tables that provide either demographic information or more general documentary reports supplement six of the case studies.

In its concern with tracing the history of the concept of citizenship in different Middle Eastern nations, and given its cross-cultural outlook, this volume is of more direct interest to scholars, researchers, professors and students in the fields of political science, anthropology, modern political and legal history in the Middle East, as well as sociology, cultural studies and comparative gender studies. I recommend it as a major contribution to the understanding and analysis of the workings of laws and practices of citizenship in the Middle East in relation to gender. 